\title{
SISTEM MONITORING KUALITAS AIR DANAU SIOMBAK MENGGUNAKAN ARDUINO UNO
}

\author{
Herdianto
}

\author{
Universitas Pembangunan Panca Budi \\ Jln. Jenderal Gatot Subroto Km.4.5 Medan \\ herdianto0108047703@gmail.com
}

\begin{abstract}
Abstrak- Danau Siombak memiliki luas 40 hektare dengan kedalaman 12 meter terletak di Kelurahan Payah Pasir Kecamatan Medan Marelan Sumatera Utara. Saat ini Danau Siombak difungsikan sebagai daerah resapan air pengendali banjir, area penangkapan ikan dan tambak penduduk sekitar serta menjadi tempat wisata. Tetapi akhir tahun 2019 kualitas air Danau Siombak sangat buruk dikarenakan ratusan bangkai babi yang dibuang di perairan danau tersebut. Akibatnya banyak ikan dan hasil tambak yang mati, bau busuk serta matinya industry wisata. Oleh karena itu penelitian ini bertujuan merancang sebuah sistem yang dapat memonitoring dan memberikan informasi mengenai kualitas air Danau Siombak dengan parameter yang dimonitoring yaitu tingkat kekeruhan air, suhu, tingkat keasaman (pH), oksigen terlarut (DO) dan padatan terlarut (TDS). Metode yang digunakan pada penelitian ini aplikasi demonstrasi. Dari 2 pengujian yang telah dilakukan diketahui untuk pengujian implementasi skema rangkaian menunjukkan tingkat ketepatan sensor mencapai $100 \%$ sedangkan pengujian sistem secara keseluruhan mencapai $\mathbf{9 0} \%$.
\end{abstract}

Kata Kunci- monitoring, kualitas, danau, metode, pengujian.

Abstract- Lake Siombak has an area of 40 hectares with a depth of 12 meters located in Kelurahan Payah Pasir, Medan Marelan District, North Sumatra. At present, Siombak Lake functions as a flood control water catchment area, fishing area and ponds surrounding residents and become tourist attractions. But by the end of 2019 the quality of Lake Siombak water was very poor due to the hundreds of dead pigs that were dumped in the lake's waters. As a result, many fish and ponds are dead, stinking and death of the tourism industry. Therefore this study aims to design a system that can monitor and provide information about the quality of Lake Siombak water with parameters that are monitored namely the level of turbidity of water, temperature, acidity (pH), dissolved oxygen (DO) and Total Dissolved Solids (TDS). The method used in this study is a demonstration application. From the 2 tests that have been carried out it is known to test the implementation of the circuit schematic showing the level of sensor accuracy reaches $100 \%$ while the overall system testing reaches $90 \%$.

Keywords - monitoring, quality, lake, method, testing.

\section{PENDAHULUAN}

Danau Siombak merupakan danau buatan memiliki luas 40 hektare dengan kedalaman 12 meter terletak di Kelurahan Payah Pasir Kecamatan Medan Marelan Sumatera Utara. Dari hasil penelitian [1] diketahui setidaknya ada 10 jenis ikan, 1 jenis udang dan 1 jenis kepiting yang dapat ditemukan di Danau Siombak sehingga sampai saat ini Danau Siombak dijadikan masyarakat sekitar sebagai daerah penangkapan ikan, kepiting dan tambak udang. Selain itu Danau Siombak juga dijadikan sebagai daerah resapan air pengendali banjir dan tujuan wisata bagi masyarakat Kota Medan dan sekitarnya. Akan tetapi pada akhir tahun 2019 kualitas air Danau Siombak sangat buruk dikarenakan ratusan bangkai babi yang dibuang di perairan danau tersebut. Akibat dari buruknya kualitas air danau, langsung dirasakan oleh masyarakat sekitar seperti banyaknya ikan dan hasil tambak yang mati, bau busuk serta matinya industry wisata. Sampai saat ini belum ada sistem monitoring kualitas air danau yang dipasang di perairan Danau Siombak sehingga masyarakat sekitar danau tidak mengetahui tingkat pencemaran air danau yang telah terjadi. Sehingga hal inilah yang mendasari masyarakat sekitar danau tidak melakukan upaya - upaya pencegahan dini untuk menghambat pencemaran air danau agar tidak menjadi lebih luas.

Beberapa penelitian mengenai sistem monitoring kualitas air telah dilakukan beberapa peneliti sebelumnya seperti yang dilakukan oleh [2], [3], [4]. Penelitian yang dilakukan [2] pada tahun 2014 bertujuan merancang system monitoring kualitas air danau dengan menggunakan sensor network wireless berbasis teknologi Zigbee dengan parameter yang diukur $\mathrm{pH}$, suhu dan kekeruhan air. Lalu pada tahun 2016 ada juga penelitian terkait monitoring kualitas air yang dilakukan [3]. Penelitian ini membahas penggunaan Internet of Thing (IoT) dalam monitoring kualitas air dengan parameter yang diukur $\mathrm{pH}$ air. 
Page |172 jaringan saraf tiruan dan belief rules based untuk dibandingkan dengan nilai standar. Apabila nilai parameter terukur melebihi nilai batas ambang maka akan dikirim Send Message Short (SMS) peringatan.

Pada penelitian ini peneliti mencoba merancang sistem monitoring kualitas air Danau Siombak dengan parameter yang diukur kekeruhan air, suhu, tingkat $\mathrm{pH}, \mathrm{DO}$ dan TDS menggunakan Arduino Uno dengan pengiriman nilai parameter air terukur menggunakan SMS.

\section{METODOLOGI}

Agar penelitian ini dapat selesai sesuai dengan waktu yang ditetapkan dan tercapainya tujuan penelitian maka peneliti menyusun langkah - langkah penelitian seperti Gbr 1 .

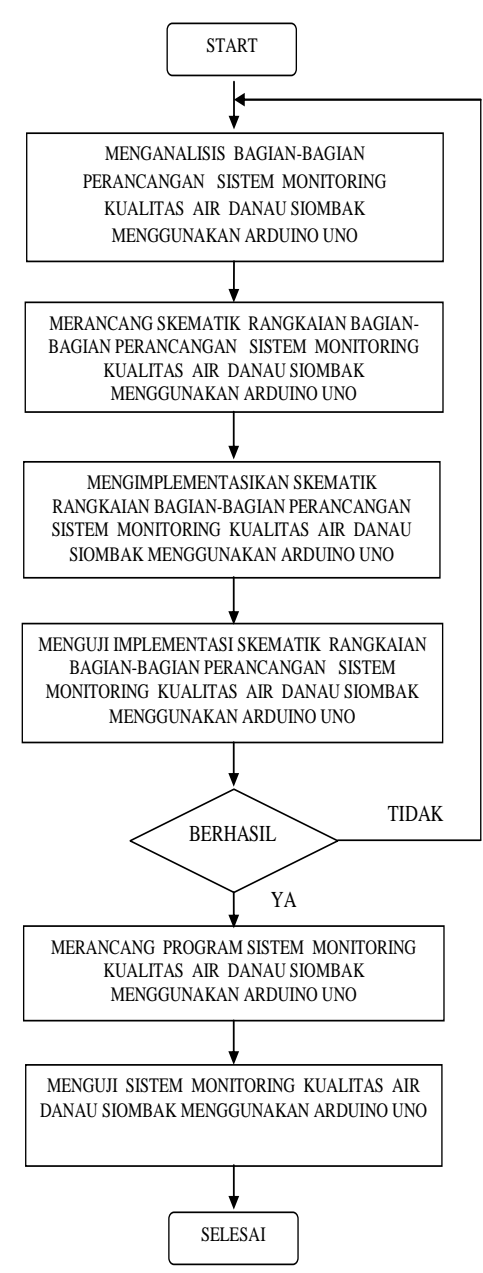

Gbr. 1 Langkah - langkah penelitian
Adapun maksud metode aplikasi demontrasi yang digunakan pada penelitian ini yaitu peneliti merancang rangkaian skematika dari bagian - bagian system monitoring kualitas air Danau Siombak selanjutnya diimplementasikan dan diuji untuk mengetahui untuk tingkat keberhasilan dari setiap bagian system monitoring yang telah dimplementasikan. Jika dari hasil pengujian tersebut tingkat keberhasilan dari setiap bagian system monitoring kualitas air Danau Siombak belum mencapai nilai yang diinginkan maka dilakukan perbaikan dan jika telah tercapai dilanjutkan ke langkah penelitian berikutnya.

\section{HASIL DAN PEMBAHASAN}

Sistem monitoring kualitas air Danau Siombak menggunakan arduino uno terbagi menjadi 2 bagian yaitu bagian perangkat keras (arsitektur) dan lunak. Untuk bentuk rancangan perangkat kerasnya seperti terlihat pada Gbr 2.

\section{A. Arsitektur Sistem Monitoring Kualitas Air Danau}

Adapun cara kerja system monitoring kualitas air Danau Siombak menggunakan arduino uno adalah sebagai berikut 5 (lima) sensor yang digunakan untuk memonitoring kualitas air akan mengirim nilai variabel yang terukur ke arduino uno untuk selanjutnya nilai variabel tersebut dimanipulasi oleh arduino uno agar dapar ditampilkan pada layar LCD dan dikirim ke server dengan komunikasi SMS.

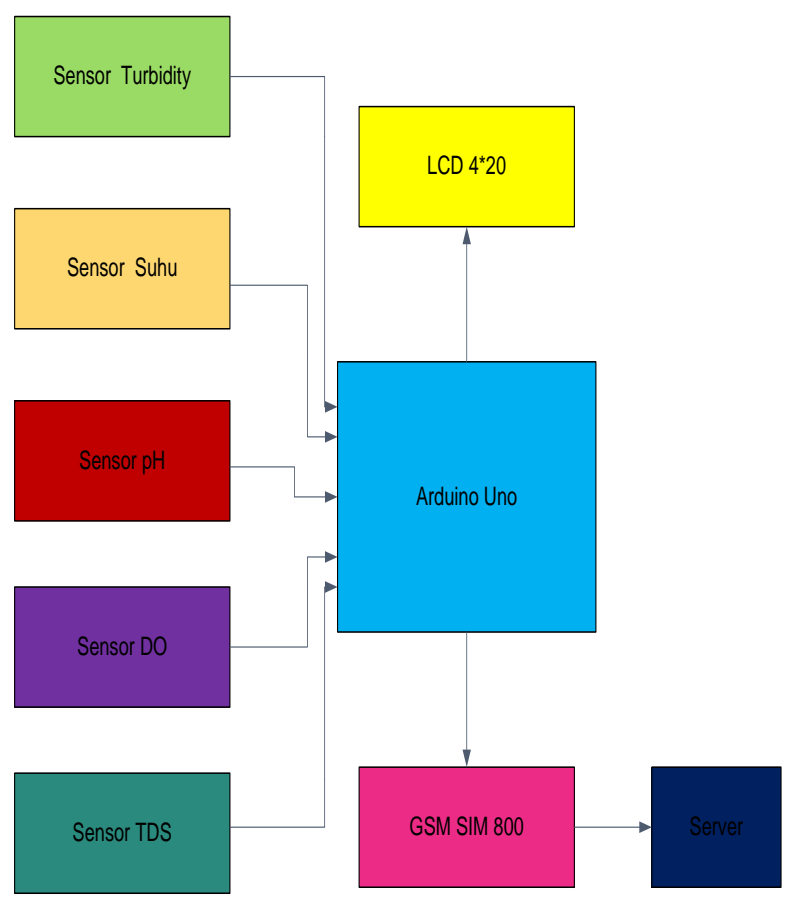

Gbr. 2 Arsitektur Sistem Monitoring Kualitas Air Danau

\section{1) Sensor}

Ada pun jenis dan jumlah sensor yang digunakan pada penelitian ini seperti terlihat pada Tabel I. 
TABEL I

SENSOR YANG DIGUNAKAN

Page | 173

\begin{tabular}{|c|c|c|c|}
\hline \multirow{2}{*}{ No } & \multicolumn{3}{|c|}{ Sensor } \\
\cline { 2 - 4 } & $\begin{array}{c}\text { Nama } \\
\text { Sensor }\end{array}$ & Jenis & $\begin{array}{c}\text { Jumlah } \\
\text { (buah) }\end{array}$ \\
\hline 1 & Turbidity & $\begin{array}{c}\text { Turbidity sensor } \\
\text { SKU SEN 0189 }\end{array}$ & 1 \\
\hline 2 & Suhu & $\begin{array}{c}\text { DS18B20 } \\
\text { waterproof }\end{array}$ & 1 \\
\hline 3 & $\mathrm{pH}$ & $\begin{array}{c}\text { pH meter SKU SEN } \\
\text { 0161 }\end{array}$ & 1 \\
\hline 4 & DO & $\begin{array}{c}\text { Dissolved Oxygen } \\
\text { Sensor SKU SEN } \\
\text { 0237 }\end{array}$ & 1 \\
\hline 5 & TDS & $\begin{array}{c}\text { Gravity Analog TDS } \\
\text { Sensor Meter For } \\
\text { Arduino SKU SEN } \\
\text { 0244 }\end{array}$ & 1 \\
\hline
\end{tabular}

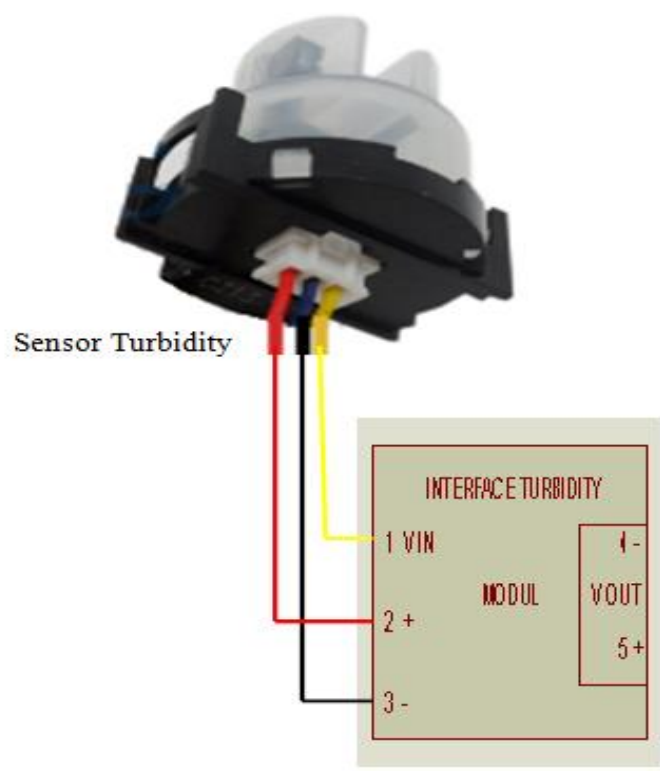

Gbr. 3 Pemasangan antara sensor turbidity dengan interface dan Arduino Uno

\section{Keterangan :}

1 terminal masukan + dari sensor turbidity

2 terminal +5 VDC dari sumber catu daya

3 terminal - dari sumber catu daya

4 terminal keluaran - interface ke arduino uno pin GND

5 terminal keluaran + interface ke arduino uno pin A0

Di dalam sensor turbidity terdapat bagian pemancar dan penerima infra merah. Untuk mengukur tingkat kekeruhan air sensor ini menggunakan prinsip jumlah intensitas cahaya infra merah yang mengenai permukaan bagian penerima. Jadi apabila kondisi air jernih berarti cahaya yang mengenai penampang penerima semakin besar dan bila air keruh berarti semakin sedikit cahaya yang mengenai penampang penerima.

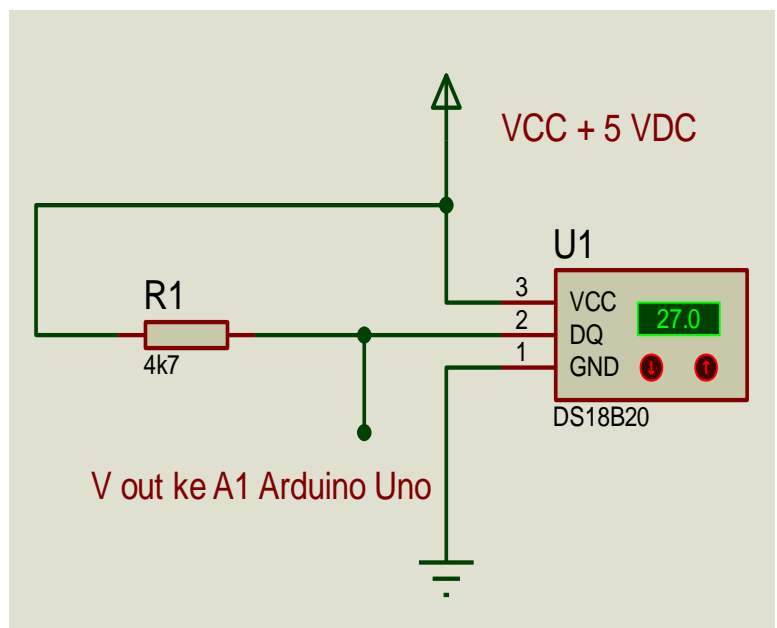

Gbr. 4 Pemasangan antara sensor suhu dengan Arduino Uno

Keterangan :

1 terminal + 5 VDC dari sumber catu daya

2 terminal keluaran + sensor ke arduino uno pin A1

3 terminal - dari sumber catu daya

Sensor ini dapat mengukur suhu -55 hingga $1250 \mathrm{C}$ dengan pengiriman data suhu terukur menggunakan teknologi 1 wire dengan panjang 12 bit.

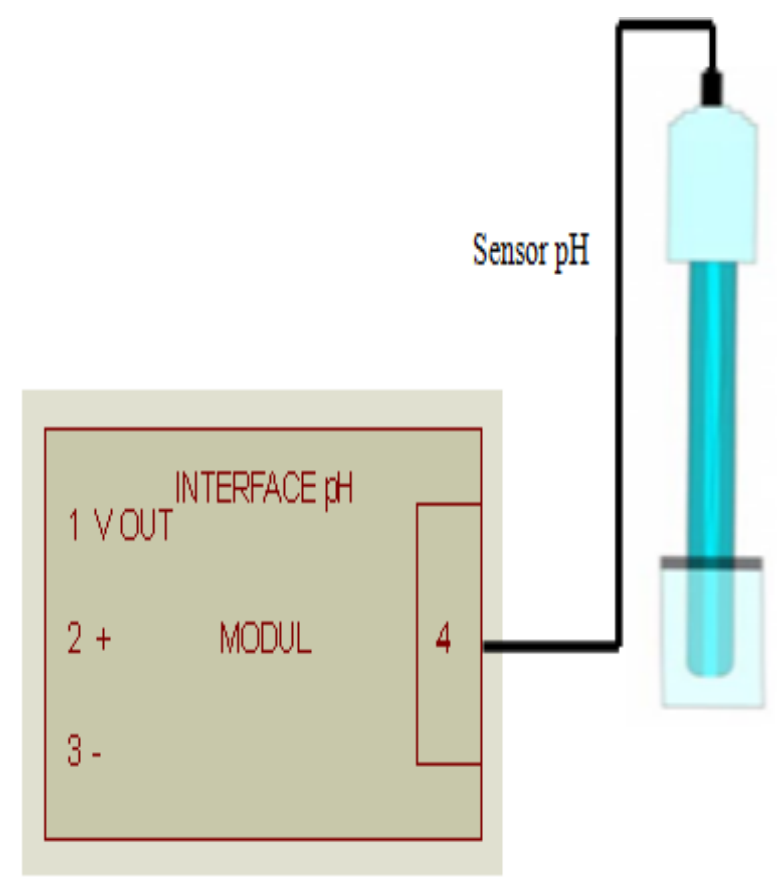

Gbr. 5 Pemasangan antara sensor $\mathrm{pH}$ dengan Arduino Uno

\section{Keterangan :}

1 terminal keluaran + interface ke arduino uno pin A2

2 terminal +5 VDC dari sumber catu daya

3 terminal - dari sumber catu daya

4 terminal probe sensor $\mathrm{pH}$ 


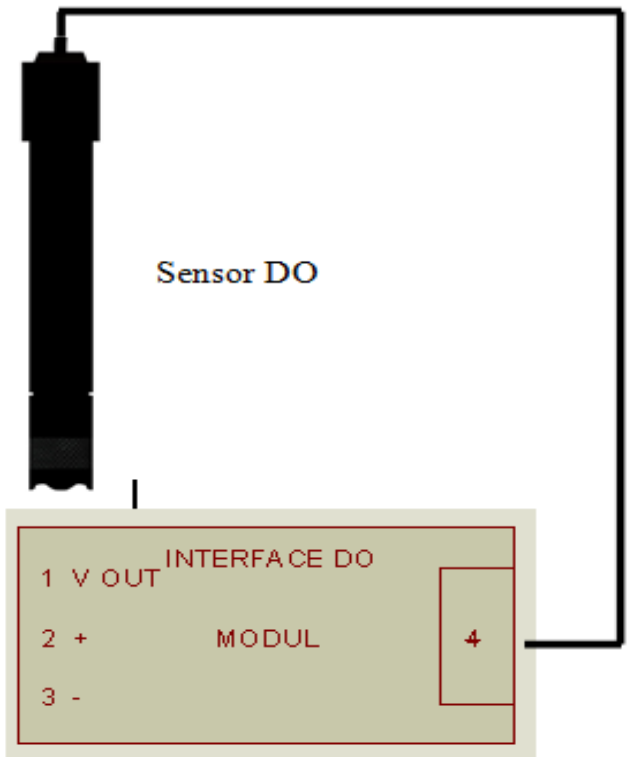

Gbr. 6 Pemasangan antara sensor DO dengan Arduino Uno

\section{Keterangan :}

1 terminal keluaran + interface ke arduino uno pin A3

2 terminal +5 VDC dari sumber catu daya

3 terminal - dari sumber catu daya

4 terminal probe sensor DO

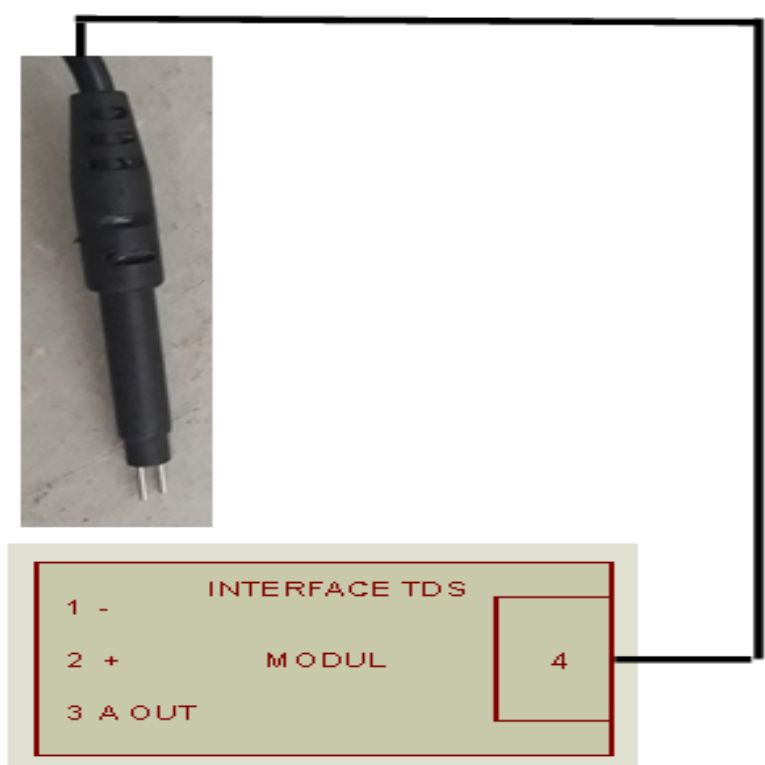

Gbr. 7 Pemasangan antara sensor TDS dengan Arduino Uno

Keterangan :

1 terminal - dari sumber catu daya

2 terminal +5 VDC dari sumber catu daya

3 terminal keluaran + interface ke arduino uno pin A4

4 terminal probe sensor TDS
2) Arduino Uno

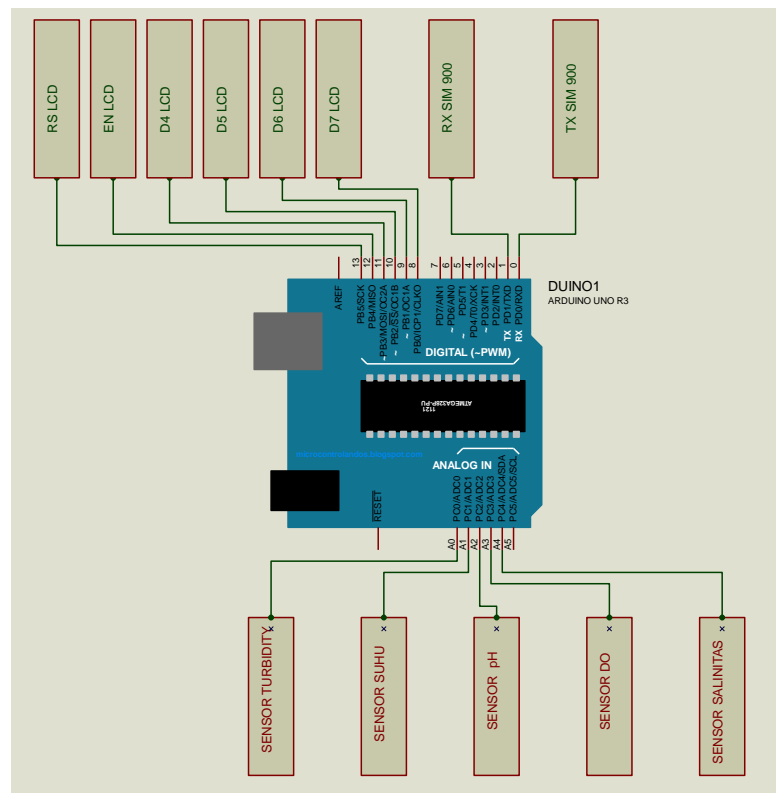

Gbr. 8 Pemasangan antara arduino uno dengan sensor, LCD dan SIM 900

\section{Keterangan :}

PB0 arduino uno dihubungkan ke D7 LCD

PB1 arduino uno dihubungkan ke D6 LCD

PB2 arduino uno dihubungkan ke D5 LCD

PB3 arduino uno dihubungkan ke D4 LCD

PB4 arduino uno dihubungkan ke EN LCD

PB5 arduino uno dihubungkan ke RS LCD

PD0 arduino uno dihubungkan ke TX SIM 900

PD1 arduino uno dihubungkan ke RX SIM 900

PC0 arduino uno dihubungkan ke sensor turbidity

PC1 arduino uno dihubungkan ke sensor suhu

PC2 arduino uno dihubungkan ke sensor $\mathrm{pH}$

PC3 arduino uno dihubungkan ke sensor DO

PC4 arduino uno dihubungkan ke sensor salinitas

\section{3) $L C D 4 * 20$}

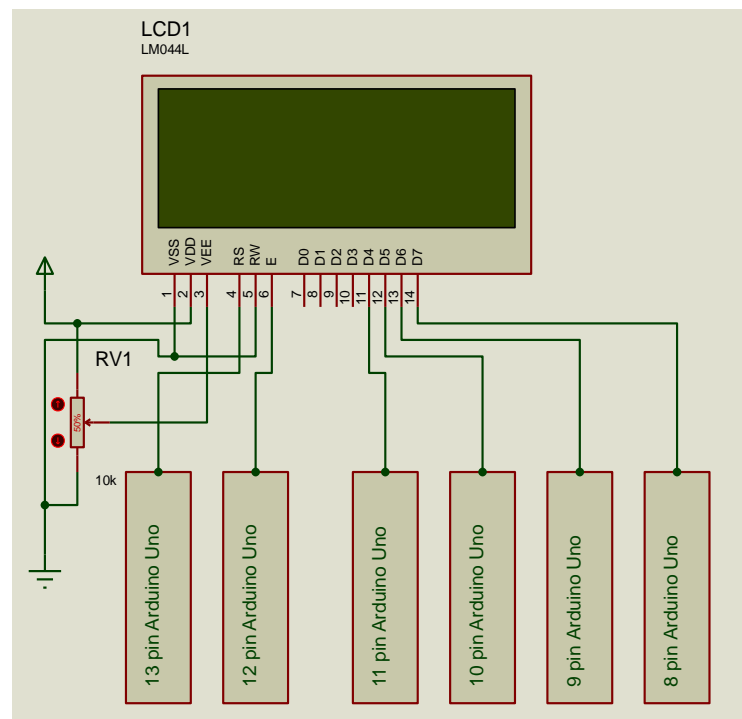

Gbr. 9 Pemasangan antara arduino uno dengan LCD 
Keterangan :

8 pin (PB0) arduino uno dihubungkan ke D7 LCD 9 pin (PB1) arduino uno dihubungkan ke D6 LCD 10 pin (PB2) arduino uno dihubungkan ke D5 LCD 11 pin (PB3) arduino uno dihubungkan ke D4 LCD Page | 17512 pin (PB4) arduino uno dihubungkan ke EN LCD 13 pin (PB5) arduino uno dihubungkan ke RS LCD

\section{4) Modul SIM 900}

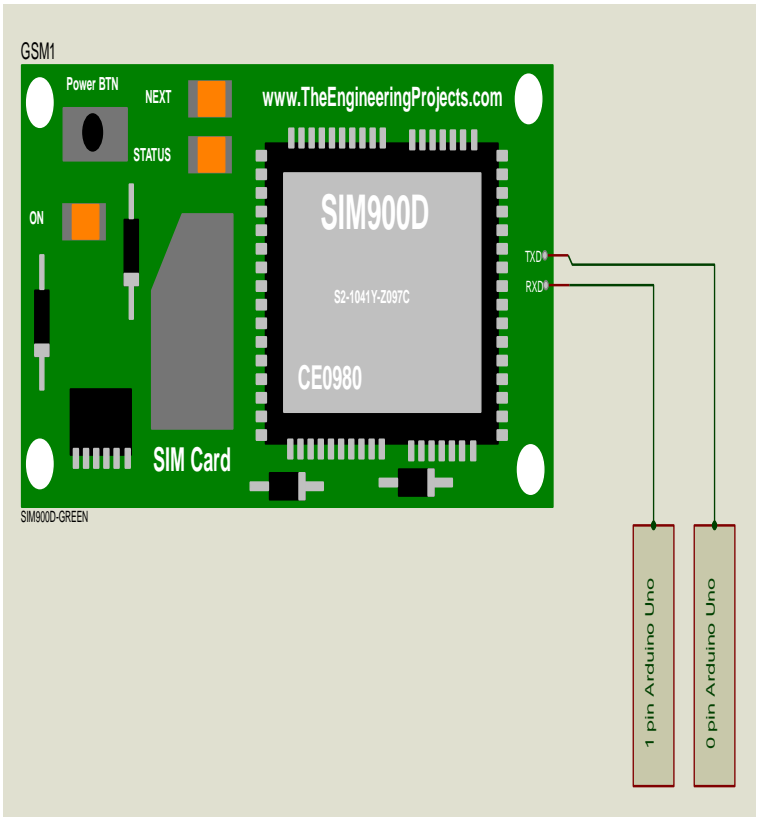

Gbr. 10 Pemasangan antara arduino uno dengan modul SIM 900 Keterangan :

0 pin PD0 arduino uno dihubungkan ke TX SIM 900 1 pin PD1 arduino uno dihubungkan ke RX SIM 900

5) Catu daya

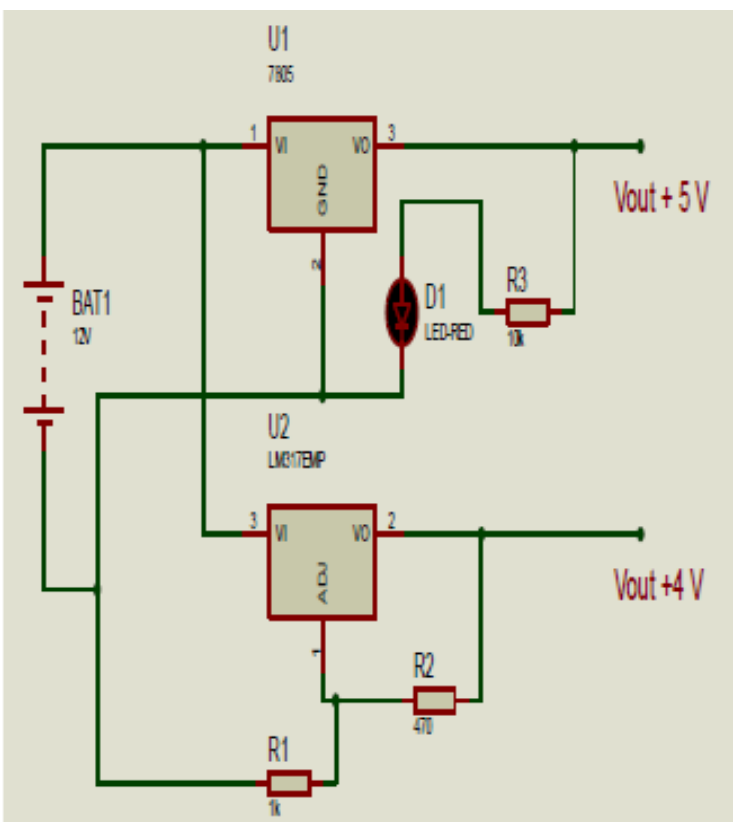

Gbr. 11 Rangkaian catu daya untuk modul SIM 900 [5]

\section{B. Perangkat Lunak}

Agar rancangan perangkat keras seperti Gbr.2 dapat berfungsi secara keseluruhan maka harus ada perangkat lunak yang dimasukkan ke dalam memori flash arduino uno. Adapun bentuk dari alur program utama dari perangkat lunak yang dirancang pada sistem monitoring kualitas air danau Siombak seperti Gbr 11.

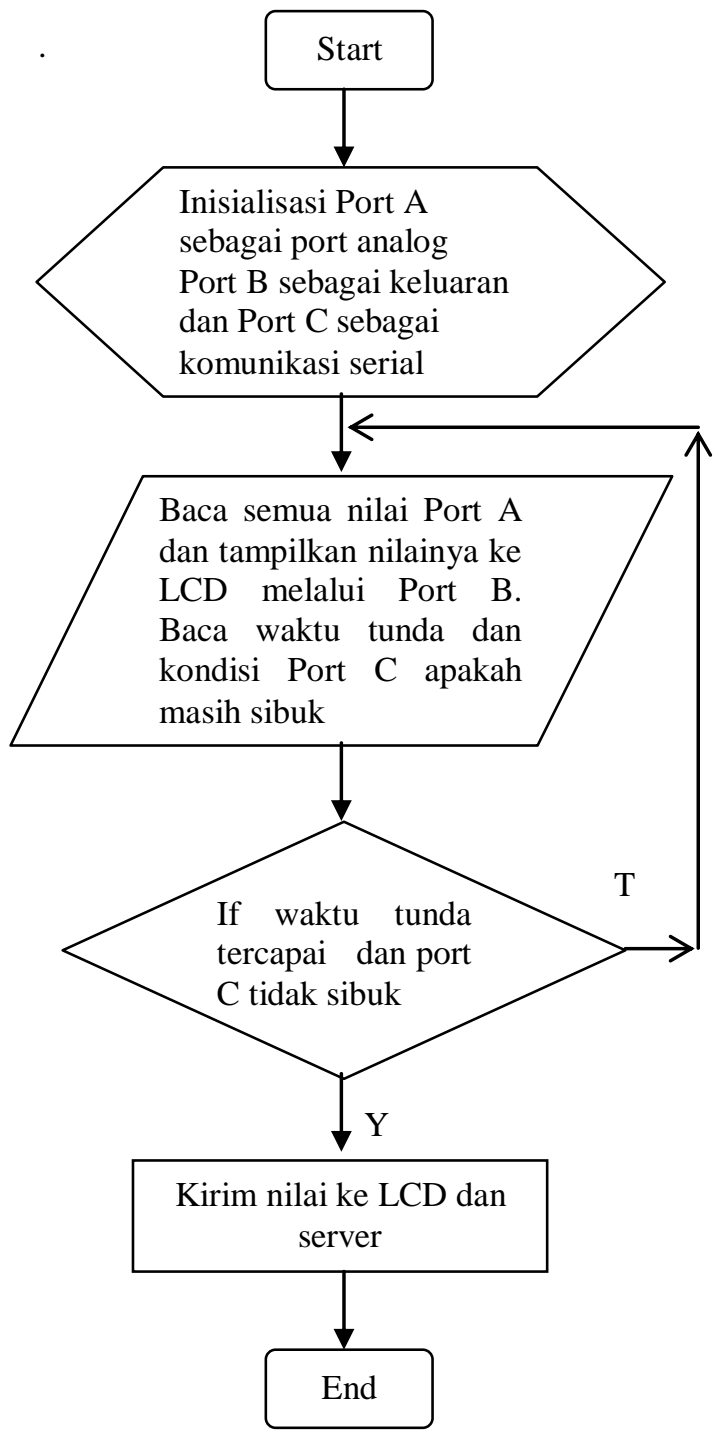

Gbr. 12 Flowchart perangkat lunak sistem monitoring kualitas air Danau Siombak menggunakan Arduino Uno

\section{Pengujian}

Untuk mengetahui apakah rangkaian pada Gbr 3.telah berfungsi dengan baik atau belum maka diuji dengan 3 level tingkat kekeruhan air yang masing masing bersumber dari air minum kemasan aqua, air sumur galian dan sawah. Dari hasil uji coba diperoleh hasil pengukuran seperti Tabel II. 
TABEL II

PENGUKURAN KEKERUHAN AIR MENGGUNAKAN SENSOR TURBIDITY

\begin{tabular}{|c|c|c|c|}
\hline \multirow{2}{*}{ No } & \multicolumn{3}{|c|}{ Sensor Turbidity } \\
\cline { 2 - 4 } & Sumber air & $\begin{array}{c}\text { Nilai rata -rata } \\
\text { (volt) }\end{array}$ & $\begin{array}{c}\text { Jumlah } \\
\text { pengukuran }\end{array}$ \\
\hline 1 & Aqua & 4,0 & 10 \\
\hline 2 & Sumur galian & 2,7 & 10 \\
\hline 3 & Sawah & 1,5 & 10 \\
\hline
\end{tabular}

Untuk menguji rangkaian pada Gbr 4. dilakukan dengan cara mencelupkan sensor suhu DS18B20 ke dalam air yang dipanaskan secara bertahap hingga suhu $40^{\circ} \mathrm{C}$ dan membandingkan hasil pengukuran terukur dengan dengan thermometer gelas. Dari hasil uji coba diperoleh hasil pengukuran seperti Tabel 3 .

TABEL III

PENGUKURAN SUHU AIR MENGGUNAKAN SENSOR DS18B20

\begin{tabular}{|c|c|c|c|}
\hline \multirow{2}{*}{ No } & \multicolumn{3}{|c|}{ Sensor Suhu } \\
\cline { 2 - 4 } & DS18B20 & $\begin{array}{c}\text { Thermometer } \\
\text { gelas }\left({ }^{0} \mathrm{C}\right)\end{array}$ & $\begin{array}{c}\text { Jumlah } \\
\text { pengukuran }\end{array}$ \\
\hline 1 & 20 & 20 & 10 \\
\hline 2 & 22,5 & 22,5 & 10 \\
\hline 3 & 24 & 24 & 10 \\
\hline 4 & 26 & 26,5 & 10 \\
\hline 5 & 28,5 & 28,5 & 10 \\
\hline 6 & 30,5 & 30 & 10 \\
\hline 7 & 32 & 32,5 & 10 \\
\hline 8 & 34,5 & 34,5 & 10 \\
\hline 9 & 36 & 36 & 10 \\
\hline 10 & 38 & 38,5 & 10 \\
\hline
\end{tabular}

Sebelum dilakukan pengujian rangkaian pada Gbr 5. terdahulu elektroda sensor $\mathrm{pH}$ dibersihkan dengan air bersih. Selanjutnya dilakukan pengukuran pada suhu $25^{\circ} \mathrm{C}$ dengan cara mencelupkan sensor ke dalam air. Dari hasil uji coba diperoleh hasil pengukuran seperti Tabel IV.

TABEL IV

PENGUKURAN KEASAMAN AIR MENGGUNAKAN SENSOR $\mathrm{pH}$

\begin{tabular}{|c|c|c|c|}
\hline \multirow{2}{*}{ No } & \multicolumn{3}{|c|}{ Sensor pH } \\
\cline { 2 - 4 } & Nilai $\mathrm{pH}$ & $\begin{array}{c}\text { Keluaran rata- } \\
\text { rata sensor }(\mathrm{mV})\end{array}$ & $\begin{array}{c}\text { Jumlah } \\
\text { pengukuran }\end{array}$ \\
\hline 1 & 0 & 416,2 & 10 \\
\hline 2 & 1 & 355,5 & 10 \\
\hline 3 & 2 & 297,3 & 10 \\
\hline 4 & 3 & 240,2 & 10 \\
\hline 5 & 4 & 179,1 & 10 \\
\hline 6 & 5 & 120,7 & 10 \\
\hline 7 & 6 & 60,1 & 10 \\
\hline 8 & 7 & 0,5 & 10 \\
\hline 9 & 8 & $-56,1$ & 10 \\
\hline 10 & 9 & $-120,6$ & 10 \\
\hline
\end{tabular}

Adapun bentuk pengujian yang dilakukan pada Gbr 6. dengan melakukan pengukuran besar tegangan pada keluaran modul interface pada suhu air $25^{\circ} \mathrm{C}$ dengan selang pengukuran 15 menit. Dari hasil uji coba diperoleh hasil pengukuran seperti Tabel V.

TABEL V

PENGUKURAN KANDUNGAN OKSIGEN DALAM AIR MENGGUNAKAN SENSOR DO

\begin{tabular}{|c|c|c|c|}
\hline \multirow{2}{*}{ No } & \multicolumn{3}{|c|}{ Sensor DO } \\
\cline { 2 - 4 } & $\begin{array}{c}\text { Nilai DO } \\
(\mathrm{mg} / \mathrm{L})\end{array}$ & $\begin{array}{c}\text { Keluaran rata- } \\
\text { rata sensor (Volt) }\end{array}$ & $\begin{array}{c}\text { Jumlah } \\
\text { pengukuran }\end{array}$ \\
\hline 1 & 1,2 & 3,19 & 10 \\
\hline 2 & 1,5 & 3,02 & 10 \\
\hline 3 & 1,8 & 2,87 & 10 \\
\hline 4 & 2,1 & 2,71 & 10 \\
\hline 5 & 2,3 & 2,58 & 10 \\
\hline 6 & 2,5 & 2,43 & 10 \\
\hline 7 & 2,8 & 2,31 & 10 \\
\hline 8 & 3,1 & 2,19 & 10 \\
\hline 9 & 3,4 & 1,91 & 10 \\
\hline 10 & 3,7 & 1,78 & 10 \\
\hline
\end{tabular}

Adapun bentuk pengujian yang dilakukan pada Gbr 7. dengan melakukan pengukuran besar tegangan pada keluaran modul interface setiap penambahan padatan terlarut dalam wadah air yang diukur. Dari hasil uji coba diperoleh hasil pengukuran seperti Tabel VI.

TABEL VI

PENGUKURAN KANDUNGAN PADATAN TERLARUT DALAM AIR MENGGUNAKAN SENSOR TDS

\begin{tabular}{|c|c|c|c|}
\hline \multirow{2}{*}{ No } & \multicolumn{3}{|c|}{ Sensor TDS } \\
\cline { 2 - 4 } & $\begin{array}{c}\text { Nilai TDS } \\
(\mathrm{mg} / \mathrm{L})\end{array}$ & $\begin{array}{c}\text { Keluaran rata } \\
\text { rata sensor } \\
\text { (Volt) }\end{array}$ & $\begin{array}{c}\text { Jumlah } \\
\text { pengukuran }\end{array}$ \\
\hline 1 & 100 & 0,24 & 10 \\
\hline 2 & 200 & 0,48 & 10 \\
\hline 3 & 300 & 0,69 & 10 \\
\hline 4 & 400 & 0,98 & 10 \\
\hline 5 & 500 & 1,13 & 10 \\
\hline 6 & 600 & 1,47 & 10 \\
\hline 7 & 700 & 1,63 & 10 \\
\hline 8 & 800 & 1,93 & 10 \\
\hline 9 & 900 & 2,1 & 10 \\
\hline 10 & 1000 & 2,28 & \\
\hline
\end{tabular}

TABEL VII

PENGUJIAN SISTEM MONITORING KESELURUHAN

\begin{tabular}{|c|c|c|c|}
\hline \multirow[t]{2}{*}{ No } & \multicolumn{3}{|c|}{ Pengujian Sistem Monitoring Keseluruhan } \\
\hline & $\begin{array}{c}\text { Pengujian } 5 \\
\text { sensor }\end{array}$ & $\begin{array}{c}\text { Pengiriman } \\
\text { SMS nilai } 5 \\
\text { sensor }\end{array}$ & Keterangan \\
\hline 1 & $\sqrt{ }$ & $\sqrt{ }$ & Berhasil \\
\hline 2 & $\sqrt{ }$ & $\sqrt{ }$ & Berhasil \\
\hline 3 & $\sqrt{ }$ & $\sqrt{ }$ & Berhasil \\
\hline 4 & $\sqrt{ }$ & $\sqrt{ }$ & Berhasil \\
\hline 5 & $\sqrt{ }$ & $\sqrt{ }$ & Berhasil \\
\hline 6 & $\sqrt{ }$ & $\sqrt{ }$ & Berhasil \\
\hline 7 & $\sqrt{ }$ & $\mathrm{X}$ & Tidak berhasil \\
\hline 8 & $\sqrt{ }$ & $\sqrt{ }$ & Berhasil \\
\hline 9 & $\sqrt{ }$ & $\sqrt{ }$ & Berhasil \\
\hline 10 & $\sqrt{ }$ & $\sqrt{ }$ & Berhasil \\
\hline
\end{tabular}




\section{IV.PENUTUP}

Dari hasil pengujian yang telah dilakukan diketahui perangkat keras yang dirancang telah berfungsi dengan baik dengan tingkat keberhasilan sensor mencapai $100 \%$ sedangkan untuk pengujian sistem secara keseluruhan memiliki tingkat keberhasilan hanya $90 \%$.

\section{REFERENSI}

[1] A. T. D. Muhtadi, A. Yunasfi, R. Leidonald, S. D. Sandy, A Junaidy, "Limnological Status of Lake Siombak, Medan, North Sumatra," Oseanologi dan Limnol. di Indones., vol. 1, no. 1, pp. 39-55, 2016.

[2] Shruti Sridharan, "Water Quality Monitoring System Using Wireless Sensor Networ," Int. J. Adv. Res. Electron. Commun. Eng., vol. 3, no. 4, pp. 399-402, 2014.

[3] I. U. Yuwono, Tito. Hakim, Luqman. Ardi, "The Application of Internet of Things System for Water Quality Monitoring," INTERNET Work. Indones. J., vol. 8, no. 1, pp. 49-53, 2016.

[4] M. S. H. Mohammad Salah Uddin Chowdurya, Talha Bin Emranb, Subhasish Ghosha, Abhijit Pathaka, Mohd. Manjur Alama, Nurul Absara, Karl Anderssonc, "IoT Based Realtime River Water Quality Monitoring System," in The 16th International Conference on Mobile Systems and Pervasive Computing (MobiSPC), 2019, pp. 161-168.

[5] H. Herdianto, "Sistem Monitoring Data Meteran Air Pelanggan Pdam Menggunakan Mikrokontroler Atmega 16," KOMIK, vol. 1, no. 1, pp. 33-39, 2017. 